\begin{tabular}{|c|c|}
\hline 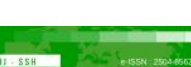 & Malaysian Journal of Social Sciences and Humanities (MJSSH) \\
\hline Malaysian Journal of & Volume 5, Issue 12, December 2020 \\
\hline (MJ-ssH) & e-ISSN : 2504-8562 \\
\hline & $\begin{array}{l}\text { Journal home page: } \\
\text { www.msocialsciences.com }\end{array}$ \\
\hline
\end{tabular}

\title{
Agriculturale Extension and Speaker Acceptance: A Simple Cross Analysis between Groups at University Stage
}

\author{
Izzah Abd Hamid ${ }^{1}$, Wan Asrina Wan Yahaya ${ }^{1}$, and Hairazi Rahim ${ }^{2}$ \\ ${ }^{1}$ Department of Crop Science, Faculty of Agricultural Science and Forestry, Universiti Putra Malaysia Bintulu Sarawak \\ Campus, 97008 Bintulu, Sarawak, Malaysia \\ ${ }^{2}$ Socio Economic, Market Intelligence \& Agribusiness Research Center, MARDI Headquarters, Persiaran MARDI-UPM, \\ 43400 Serdang, Selangor, Malaysia
}

Correspondence: Wan Asrina Wan Yahaya (asrina@upm.edu.my)

\begin{abstract}
Effective communication skills is one of the many abilities that agricultural extensionists should possess. This is because, these officers will be required to disseminate the latest knowledge and introduce new technologies to farmers to fulfil national agricultural policies and vision. Anxiety is a common issue faced by extensionists, especially during oral briefings or presentation and for officers who are still new at their job. The problem could arise from situational or personal effects, which play significant roles in regulating anxiety. Controlled anxiety allows for a remarkable speech delivery and accelerate audience attention and involvement. The study focused on determining the challenges or factors influencing the fluency/smoothness in giving speeches by academic and non-academic personnel in UPMKB. Both groups are irregularly involved in extension services to the Bintulu community. A semi-structured questionnaire was prepared and distributed among 30 respondents. This study used an in-depth interview and content analysis to highlight the challenges among respondents. Our findings indicated two main challenges, namely the occurrence of speech anxiety and insufficient preparation before speech delivery. Older and more experienced respondents ( $>16$ years job experience) showed controllable anxiety compared to the younger ones due to the younger officers limited public speaking experience. The response of the audience during agricultural talks significantly affects the respondent's anxiety by either reducing or increasing the anxiety through non-verbal communication - moreover, sufficient time to prepare the information for the speech also regulates anxiety in respondents. Therefore, invitation for agricultural extension talks or speeches must consider a speaker's expertise and provide sufficient advance notice.
\end{abstract}

Keywords: agricultural extension agent, anxiety, public speaking, non-verbal communication, semi-structured interview

\section{Introduction}

The main task of an agricultural extension agent is transferring knowledge, skills, and technology to farmers to increase farm productivity. Sharing sessions between an extension agent with farmers may be in the form of face to face discussions held during field visits, short courses, small workshops participated by 20 to 30 farmers, and video recordings for broadcast on TV (Bührer and Wroblewski, 2019). Therefore, an agricultural extension agent must possess good communication skills and be 
confident in performing the task in front of farmers from diverse socio-economy backgrounds and agricultural activities.

Public speaking among extensionists could literally affect their working performance either in positive or negative ways. A common effect caused by public speaking is anxiety, which can negatively affect the person's performance if it is uncontrollable (Docan-Morgan and Schmidt, 2012; Stein et al., 1996). Generally, anxiety behaviour is associated with a negative thought of something or responses from others such as the audience, who in this context are farmers (Cho et al., 2004). The level of anxiety increases with several factors, for example, situational or personal effects (Beatty and Behnke, 1991).

Situational anxiety caused by environmental factors such as negative audience behaviour affects the speaker's performance, which leads to increased anxiety level, accelerated self-talk, and internal physiological disturbances (Kankam and Boateng, 2017). An anxious speaker normally tends to give a shorter and poorer speech; however, this behaviour can be easily minimised and recovered with continuous rehearsals, flashcard aids, or by routinely speaking in public (Jones et al., 2012). Moreover, anxiety level decreases significantly with a positive audience behaviour who shows support for the speaker through their enjoyment of the public speech and being demonstrably appreciative and friendly (Pertaub et al., 2002). Hence, this study focused on determining the challenges or factors influencing the fluency/smoothness in giving speeches by academic and non-academic personnel in UPM Bintulu Sarawak Campus (UPMKB).

\section{Literature Review}

\section{The Roles of Agricultural Extension Officers}

Agricultural extension and advisory services performed by government agencies are not new to farmers. New and feasible knowledge, skills, and technologies gained by agricultural agencies are shared and transferred via extension officers or agents to farmers (Danso-Abbeam et al., 2018). The main objectives of agricultural extension are to boost agricultural productivity in sustainable ways, improve a farmer's income, and ultimately meet national food security. Thus, every year, it is routine for all extension officers or notably known as Agricultural Officers (AO) and Assistant Agricultural Officers (AAO) under the Department of Agriculture (DOA), Malaysia to conduct farm visits, workshops, and in-house training in various agricultural scopes. However, other government agencies tasked with the advancement of agriculture such as the Malaysian Agricultural Research and Development Institute (MARDI) and Federal Agricultural Marketing Authority (FAMA), and universities like UPM and UMT, also actively participate in improving the country's agricultural production through training sessions to educate our farmers.

The provision of an agricultural training to farmers can sometimes be a challenge because of the education gap between extension officers and farmers. Generally, most Malaysian farmers as well as those in other countries live in rural areas and are educated to secondary level (Izzah and Wan Asrina, 2019). Because of this, an extension officer must possess good communication skills and well-prepared and effective during the delivery of agricultural messages. This will ensure the farmers substantially understand the knowledge and skills taught and are able to implement them at their farms (Shah et al., 2013). However, some extension officers do experience communication and physiological problems e.g. anxiety and self-deprecation when giving public agricultural talks or speeches. This commonly happens among young officers who have just joined the agricultural institutions ( $<5$ years' experience), officers with zero or limited agricultural education background, or those who were less exposed to public speaking during their secondary and tertiary education stages.

\section{Anxiety Behaviour in Delivering a Speech}

Anxiety behaviour happens for many reasons such as overthinking or excessive fear of something which leads to increased heartbeat (Docan-Morgan and Schmidt, 2012; Slater et al., 2006; Wörtwein et al., 2015). Though the problem is normally temporary, it can affect someone's confidence level or 
worse if the condition is serious enough. Therefore, identifying the sources of anxiety is crucial as this allows a person to manage the problem.

Public speaking or talks often causes a daunting effect on the speaker and can sometimes result in anxiety. Obvious signs of anxiety during public speaking include loss of words and shaking or known as maladaptive behaviour and can affect speech performance (Shi et al., 2015). A person with higher anxiety level/problem can experience and inability to talk and displays signs such as frequent pauses, speaks in nonsense, mind going blank, and shaking (Bodie, 2010; Hancock et al., 2010). The highest anxiety level is always found before or while waiting to deliver the speech compared to the speech preparation period, which yields the lowest anxiety level. A person with high anxiety always treats public speeches as a burden in their daily tasks and this eventually affects their performance either in the speech or at work (Docan-Morgan and Schmidt, 2012).

There are several reasons for the anxiety level of the speaker, such as audience behaviour, time preparation, speaker and audience background, and using appropriate visual aids. Audience behaviour has a significant effect on speech anxiety. Positive attitudes such as nodding, clapping, and learning forward or displaying an appreciative behaviour improve speaking performance compared to negative attitudes such as looking away or head shaking (Chollet et al., 2015; Pertaub et al., 2002; Slater et al., 1999). Moreover, the relationship between time preparation and anxiety level also affects the performance of the speaker. This was emphasised by Menzel and Carrell (1994) who found a positive relationship between time spent by the speaker on preparing the material, cognitively processing information, and time for rehearsal, and the increased quality of the speech. Repetitive rehearsals such as practising out loud reflects verbalisation, clarifies thought and significantly improves the anxiety level of the speaker.

When the agricultural extension and services involve an agriculture officer and farmers, understanding the backgrounds of the speaker and audience is also crucial in controlling the anxiety and providing a meaningful public speaking experience. The speaker's background such as their expertise affects their performance, which is in line with their ability to deliver effective public speeches. The expertise may come from a higher educational background or experience gathered during public speaking or studies (Hancock et al., 2010). Moreover, an older speaker usually has gained more experience and is able to easily control and direct an audience's interests compared to a younger speaker. The use of visual aids also improves the anxiety level of the speaker and provides the audience with a clearer understanding (Menzel and Carrell, 1994).

\section{Methodology}

The study was conducted from January to March 2019 using semi-structured interviews distributed among 30 respondents comprising university staff at UPM Bintulu Sarawak Campus (UPMKB). The respondents were selected through their involvement in delivering agriculture-based speeches/talks either in UPMKB or programmes organised by the institution elsewhere. Due to their expertise and backgrounds, most of the respondents were frequently involved in lectures and briefings, and occasionally invited as speakers in agriculture training organised by the University Agricultural Park (TPU) or by local agencies found in Bintulu in courses related to crop, livestock, and aquaculture production and management. The questions were focused on personal background, how the respondent felt feeling while the program was running, early preparation, the agricultural topic and scope, and audience/farmer preference and their chosen visual aids to improve audience involvement. In this article, our focus is more on the occurrence of speech anxiety and preparation time needed to deliver a public speech in the respective agricultural areas. All respondents were involved' voluntarily, and a week's notice was sent to confirm their participation. Most of the respondents answered the questions bilingually, namely in English and Malay. Respondents who answered in Malay had their answers translated into English carefully and accurately to ensure the original answers didn't lose their meanings and the respondents' intent. This study used an in-depth interview using qualitative methods and the data was then analysed using content analysis and Statistical Package for Social Sciences (SPSS) version 23.0. 


\section{Results and Discussion}

\section{Respondentprofiling}

A total of 30 respondents, $48.15 \%$ of whom are male and $51.85 \%$ female, were interviewed in this study (Table 1). About $33.33 \%$ of the respondents were aged between 45 to 49 years old, followed by 40 to 44 years old $(29.63 \%)$, 30 to 34 years old $(22.22 \%)$, and 35 to 39 years old (14.81\%). Almost half of the respondents $(40.74 \%$ ) had $\mathrm{PhD}$ qualifications. However, about $51.86 \%$ of the respondents had $<10$ years' experience which was calculated by their service and response during the interview sessions.

Table 1: Profile of respondents

\begin{tabular}{cc}
\hline Categories & Percentage (\%) \\
Gender & 48.15 \\
Male & 51.85 \\
Female & \\
Ages & 22.22 \\
$30-34$ & 14.81 \\
$35-39$ & 29.63 \\
$40-44$ & 33.33 \\
$45-49$ & \\
& \\
Education & 3.70 \\
SPM & 11.11 \\
Certificate & 7.41 \\
Diploma & 22.22 \\
Degree & 14.81 \\
MSc & 40.74 \\
PhD & \\
& \\
Experience & 25.93 \\
<5 years & 25.93 \\
6 to 10 years & 14.81 \\
11 to 15 years & 33.33 \\
>16 years &
\end{tabular}

All the respondents gave heterogenous feedback on public speaking in agriculture themes due to different levels of educational, experience, knowledge, and environmental conditions (e.g. audience reactions or debilitative to the speaker). This has increased speech anxiety and fear towards delivering a competent agriculture public speech/talks to the targeted farmer group.

Our interview section with respondents of different backgrounds yielded two challenges. The challenges were sorted and differentiated according to the respondents' answers of either positive or negative, and the responses were taken together with detailed explanations. The first challenge was the occurrence of speech anxiety and the second factor was insufficient preparation before speaking publicly.

\section{a. The occurrence of speech anxiety}

All the respondents expressed their fear when invited to deliver an agriculture speech/talk such as stress and nervousness, which lead to anxiety behaviour. This could be attributed to their different educational backgrounds and also related to their age. Respondents below 39 years old expressed higher anxiety due to insufficient experience and lack of exposure to actual public speaking. However, 
respondents over 40 years old were calmer due to experience gained through their working years. There were significant differences between different education levels especially between academic and non-academic staff. Non-academic respondents (i.e. Agriculture Officer, Assistant Agriculture Officer, etc.) showed restless behaviour when asked to deliver agriculture talks on topics other than the general topics they were familiar with. This was highlighted by respondents 4 and 6 :

“...I only deliver agriculture speech/talks for a student for more than ten years. I never give a talk to other audience because my expertise relies on chicken managements" (Respondent 4).

“...I cannot deliver any topic which not my expertise. I only give a talk when it related to my background" (Respondent 6 ).

Other respondents expressed that due to their limited exposure to public talks, thus, they couldn't give a fair and concise assessment of their anxiety level. Both respondents were newly appointed academicians, who lack of confidence and inability to state their competency in giving a public talk, since these duties had never been assigned to them. Respondents 1 and 2 gave these answers:

“...Only involved in academic talk; conference. Other than that, I'm not involved at all because I'm a new lecturer" (Respondent 1).

"...As a new lecturer, I only deliver a talk to my student and of course, in a conference during my study" (Respondent 2).

However, respondents who were more than 40 years old showed a higher confidence and provided more reliable justification when giving agriculture speeches/talks, which is significant with their years of experience (>16 years). Moreover, the background of the audience was emphasised by them to provide clearer messages or ideas which were suitable to the audience. This was highlighted by respondents 23 and 24 :

“...I can deliver any topic as long as I know my audience's backgrounds. I will prepare all the materials before the talk, and I am confident with it" (Respondent 23).

"...Open to all audience if the organiser informed the audience background. Sometimes miscommunication between the organiser and it will trigger my nervous and affect my message delivery" (Respondent 24).

The above examples show how age, educational level, and experience play significant roles in circulating anxiety in all respondents. Longer years of service at the workplace significantly affects their anxiety level, which was also confirmed by Hancock et al. (2010) that reported older respondents were more likely to be very comfortable with public speaking compared to the younger ones. Their research did not only cover respondents' age spectrum, but also emphasised the high comfort level of educated respondents when speaking in a public setting. Non-verbal communications expressed by the audience is another reason for respondents' inability to control their anxiety. This is particularly true if excessive situational or state expressions such as a lack of interest through averted gazes or lack of backchannel behaviour and disagreement significantly increase the anxiety level of the speaker (Chollet et al., 2015; Slater et al., 2006). However, a positive audience exhibited through non-verbal communication, i.e. encouraging smiles and nods, significantly improves and reduces the anxiety level of the speakers (Pertaub et al., 2002). Most speakers prefer a positive audience behaviour in order to deliver more a remarkable talk and reduce frequent pauses, nonsense speeches, mind going blank, and shaking (Bodie, 2010; Hancock et al., 2010). Interestingly, our study has shown contradictory results with Hancock et al. (2010), that specified female speakers were more vulnerable to anxiety attack compared to male speakers stemming from constant fear and several public speaking avoidances. In contrast, our study has shown a comparable anxiety level between genders, similar to the results reported by Koç and Dündar (2018). 


\section{b. Insufficient preparation}

Most of the respondents agreed that ample preparation time, information design and delivery, and communication flow are necessary criteria for giving pleasant public speech/talks. However, more time is needed to prepare the agriculture talks in situations where the given topic is too technical or for a mixed audience (i.e. experienced and new farmers). Most of our respondents preferred agriculture topics related to their experience regardless of their educational level. However, the audience types play a significant role in circulating effective message delivery, thus affecting speaker preparation time. A short notice definitely affects the speaker's preparation time, as mentioned by respondents 7 and 12:

“... Notice $<3$ hours to replace other speaker is the hardest part as I need at least three days to prepare!" (Respondent 7).

“...I always invited by the organiser and sometimes $<4$ days' notice before the talks. I prefer at least a week to prepare for an hour session, but I accept it and further discuss with organiser to alter the topic to make it fit the available time to prepare ( $<4$ days' notice)" (Respondent 12).

Some respondents only need $<2$ hours to prepare all the materials due on their expertise and their preparation for talks is less problematic since it is considered a routine job especially for academicians. They also emphasised that type of audience affects the preparation, and sometimes they only used previously prepared materials and would edit parts of those material to fit other audience categories regardless of their education level. Respondents 10 and 27 stated:

“...General topics in agriculture will not consume my time more than 2 hours as I have all the materials with me. I formerly worked with the plantation company for seven years before I joined this institution. My focus is on student's practical, which uses similar materials every year, I need a little bit updated information if necessary" (Respondent 10).

“...My expertise is on plant and biotechnology; as long it covers my background, I can prepare as earlier as possible. I have all the presentation materials, which make it easier for me. Unless it beyond my expertise, 2 hours is impossible for me to prepare all the important information" (Respondent 27).

Most of the respondents emphasised using visual aids to engage the involvement of the audience/farmers, which also resulted in a longer preparation time as they admitted after doing a selfanalysis. The visual aids are used to capture an audience's attention and avoid negative expressions. Insufficient preparation time would affect speaker's emotional situation and leads to uncomfortable public talks. This was highlighted by respondents 3 and 9:

“...I lost my confidence and feel insecure when the audience is not paying attention to my talk. I prepared everything to help their understanding, including using a simple language and bring related aids such as video to encourage them listening to my talk" (Respondent 3).

“...I had prepared everything but aggressive audience providing feedback or even asking a question related to new financial policy always juggling my emotional situational. It gives a daunting effect to me" (Respondent 9).

Early notification not only helps the speaker (i.e. extension officer) to be prepared with respect to mind and emotion, if fact, it greatly helps the speaker to be ready when facing an audience with a large spectrum of socio-economic backgrounds by using an effective approach and message delivery. However, a short notice potentially affects the speaker's performance and is another source of self-talk, self-deprecation, and poor speech delivery (Docan-Morgan and Schmidt, 2012; Kankam and Boateng, 
2017). A good allocation of time for preparation before the talk eventually increases the speech quality when the cognitive mind has already processed related information. Menzel and Carrell (1994) showed that respondents with high trait-anxiety will reduce their sense of anxiety after being well prepared for the talks and have sufficient time to practice. However, insufficient preparation time affects the performance of the speaker. Daly et al. (1995) agreed with this through their research that restricted preparation time to only 20 minutes for their respondents, where a well-prepared/experience speaker even delivered a speech poorly. Use of visual aids such as video, meme or tools in helping to deliver the speech is encouraging by the speaker and will affect speaker performance. Through adequate preparation time, a well-experienced speaker will design a proper flow, including visual aids to capture the audience's attention and enhance their public speaking experience (Menzel and Carrell, 1994).

\section{Conclusion}

Two challenges were identified among unofficial agricultural extension speakers who worked at the university, i.e., occurrence of speech anxiety, and insufficient preparation time. These challenges have significantly affected the confidence level and speech delivery of the speakers. Inexperienced respondents ( $<5$ years) are frequently faced with several difficulties in delivering competent agriculture talks due to insufficient exposure to public speaking. Experienced respondents ( $>16$ years) with a high education level are always ready to become guest speakers according to the topic given and take it as a challenge compared to officers with a lower education level (i.e. agriculture certificate) who prefer topics within their expertise. Sufficient preparation time is vital among speakers to design an effective agricultural talk aided by visual aids. This reducing problems such as anxiety, self-talk, and selfdeprecation.

\section{Acknowledgement}

The authors would like to thank the students of Diploma in Agriculture registered for Agricultural Extension (CES2241) courses in Universiti Putra Malaysia Bintulu Sarawak Campus who helped in conducting the interviews. Our appreciation also goes to all the respondents who supported and cooperated in this effort to its end through documentation of the findings and Madam Siti Fatimah Razali who assisted and facilitated this documentation.

\section{References}

Beatty, M.J., \& Behnke, R.R. (1991). Effects of public speaking trait anxiety and intensity of speaking task on heart rate during performance. Human Communication Research, 18: 147-176.

Bodie, G.D. (2010). A racing heart, rattling knees, and ruminative thoughts: Defining, explaining, and treating public speaking anxiety. Communication Education, 59: 70-105.

Bührer, S., \& Wroblewski, A. (2019). The practice and perceptions of RRI-A gender perspective. Evaluation and Program Planning, 77: 101717.

Cho, Y., Smits, J.A.J., \& Telch, M.J. (2004). The speech anxiety thoughts inventory: scale development and preliminary psychometric data. Behaviour Research and Therapy, 42: 13-25.

Chollet, M., Wörtwein, T., Morency, L.P., Shapiro, A., \& Scherer, S. (2015). Exploring feedback strategies to improve public speaking: An interactive virtual audience framework. In "ACM International Joint Conference on Pervasive and Ubiquitous Computing", pp. 1143-1154. ACM, Osaka, Japan.

Daly, J.A., Vangelisti, A.L., \& Weber, D.J. (1995). Speech anxiety affects how people prepare speeches: A protocol analysis of the preparation processes of speakers. Communications Monographs, 62: 383-397.

Danso-Abbeam, G., Ehiakpor, D.S., \& Aidoo, R. (2018). Agricultural extension and its effects on farm productivity and income: insight from Northern Ghana. Agriculture \& Food Security, 7: 1-10. 
Docan-Morgan, T., \& Schmidt, T. (2012). Reducing public speaking anxiety for native and non-native English speakers: The value of systematic desensitization, cognitive restructuring, and skills training. Cross-Cultural Communication, 8: 16-19.

Hancock, A.B., Stone, M.D., Brundage, S.B., \& Zeigler, M.T. (2010). Public speaking attitudes: Does curriculum make a difference? Journal of Voice, 24: 302-307.

Izzah, A.H., \& Wan Asrina, W.Y. (2019). Levels of involvement and understanding in agriculture: The case of Bintulu, Sarawak, Malaysia. International Journal of Humanities and Social Science Research 5: 201-206.

Jones, C.R., Fazio, R.H., \& Vasey, M.W. (2012). Attentional control buffers the effect of publicspeaking anxiety on performance. Social Psychological and Personality Science, 3: 556-561.

Kankam, P.K., \& Boateng, S.O. (2017). Addressing the problem of speech anxiety among students. International Journal of Public Leadership, 13: 26-39.

Koç, M., \& Dündar, A. (2018). Research on social anxiety level and communication skills of secondary school students. Asian Journal of Education and Training, 4: 257-265.

Menzel, K.E., \& Carrell, LJ. (1994). The relationship between preparation and performance in public speaking. Communication Education, 43: 17-26.

Pertaub, D.P., Slater, M. \& Barker, C. (2002). An experiment on public speaking anxiety in response to three different types of virtual audience. Presence: Teleoperators \& Virtual Environments, 11: 68-78.

Shah, J.A., Asmuni, A., \& Ismail, A. (2013). Roles of extension agents towards agricultural practice in Malaysia. International Journal on Advanced Science, Engineering and Information Technology, 3: 59-63.

Shi, X., Brinthaupt, T.M., \& McCree, M. (2015). The relationship of self-talk frequency to communication apprehension and public speaking anxiety. Personality and Individual Differences, 75: 125-129.

Slater, M., Pertaub, D.P., Barker, C., \& Clark, D.M. (2006). An experimental study on fear of public speaking using a virtual environment. CyberPsychology \& Behavior, 9: 627-633.

Slater, M., Pertaub, D.P., \& Steed, A. (1999). Public speaking in virtual reality: Facing an audience of avatars. Computer Graphics and Applications, 19: 6-9.

Stein, M.B., Walker, J.R., \& Forde, D.R. (1996). Public-speaking fears in a community sample: Prevalence, impact on functioning, and diagnostic classification. Archives of General Psychiatry, 53: 169-174.

Wörtwein, T., Morency, LP., \& Scherer, S. (2015). Automatic assessment and analysis of public speaking anxiety: A virtual audience case study. In "International Conference on Affective Computing and Intelligent Interaction (ACII)", pp. 187-193. IEEE Computer Society Washington, Xian, China. 